\title{
Understanding the utilization of primary health care services by Indigenous men: a systematic review
}

\author{
Kootsy Canuto ${ }^{1,2,3^{*}}$ D. Alex Brown ${ }^{1,3,4}$, Gary Wittert ${ }^{2}$ and Stephen Harfield ${ }^{1,3}$
}

\begin{abstract}
Background: Aboriginal and Torres Strait Islander men experience worse health outcomes and are the most marginalized and disadvantaged population group in Australia. Primary health care services are critical to providing both clinical and social and emotional support, however, remain underutilized by Aboriginal and Torres Strait Islander men. This review aims to better understand the utilization of primary health care services by Indigenous men and assess the effectiveness of strategies implemented to improve utilization.
\end{abstract}

Methods: A four-step search strategy was employed across four databases to find peer-reviewed publications and grey literature from Australia, New Zealand, Canada and America. The search began in March 2015 and included the following databases PubMed, CINAHL, Informit (Indigenous collection) and Embase. Additional databases and websites were also searched for grey literature, reference lists of included publications were searched for additional studies and relevant experts were consulted.

Results: The literature search found seven articles that met the inclusion criteria; four describing three research projects, plus three expert opinion pieces. The search was unable to find published research on strategies implemented to improve primary health care utilization by Indigenous men.

There is limited published research focused on the utilization of primary health care by Indigenous men. From the identified papers Indigenous men described factors impacting utilization which were categorized into three primary organizing themes; those related to health services, the attitudes of Indigenous men and knowledge. It is evident from the identified papers that improvements in Indigenous health can only occur if future programs are developed in collaboration with health services and Indigenous men to address differing requirements.

Conclusions: Currently, health systems in Australia are limited in their ability to improve the health and wellbeing of Aboriginal and Torres Strait Islander males without such strategies. Future research should focus on evaluating the implementation of men specific utilization strategies. It is through evidence-based research that subsequent policies and programs can be made and implemented to improve Indigenous men's health.

Keywords: Indigenous, Aboriginal, Torres Strait islander, Men, Utilization, Primary health care

\footnotetext{
* Correspondence: Kootsy.Canuto@sahmri.com

${ }^{1}$ Wardliparingga Aboriginal Research Unit, South Australian Health and

Medical Research Institute, Adelaide, Australia

${ }^{2}$ Freemasons Foundation Centre for Men's Health, University of Adelaide,

Adelaide, Australia

Full list of author information is available at the end of the article
}

(c) The Author(s). 2018 Open Access This article is distributed under the terms of the Creative Commons Attribution 4.0 International License (http://creativecommons.org/licenses/by/4.0/), which permits unrestricted use, distribution, and reproduction in any medium, provided you give appropriate credit to the original author(s) and the source, provide a link to the Creative Commons license, and indicate if changes were made. The Creative Commons Public Domain Dedication waiver (http://creativecommons.org/publicdomain/zero/1.0/) applies to the data made available in this article, unless otherwise stated. 


\section{Background}

Like other Indigenous peoples from colonized countries including New Zealand, Canada and the Unites States of America, Aboriginal and Torres Strait Islander people experience worse health outcomes than their non-Indigenous counterparts [1]. Although there have been improvements in the life expectancy among Australian males in the last 30 years, there has been little improvement noted in the life expectancy gap between Aboriginal and Torres Strait Islander men and their non-Indigenous counterparts, currently estimated to be 10.6 years [2, 3]. Although there are issues with comparing data across countries [4], the data clearly shows life expectancy gaps between Indigenous peoples from Australia, New Zealand, Canada and America and their non-Indigenous counterparts [5].

Against virtually all markers of health and social status, across the life span, Aboriginal and Torres Strait Islander people are the most marginalized and disadvantaged in Australian society [6]. Internationally, the health disparities of Aboriginal and Torres Strait Islander people "are as large as those seen in any other high-income country"[7] (p. 1). Aboriginal and Torres Strait Islander men are at a particularly elevated risk of psychological illness, drug and alcohol issues, engagement with the justice system, suicide and self-harm [810]. These issues not only contribute to poor quality of life, but contribute to the onset and severity of a range of health conditions, including cardiovascular and metabolic diseases [9].

Adverse historical and contemporary traumas experienced by Aboriginal and Torres Strait Islander men have been directly linked to their current adverse health profiles $[11,12]$. The enduring sociocultural effects of colonization continues to have a detrimental effect on the health and social and emotional wellbeing of Indigenous people [13-19]. Prior to colonization Indigenous men and women "had defined roles according to age and gender"[19] (p.5). Colonization significantly altered the role of the Indigenous man [8, 20-23]. Traditional power and authority that Indigenous men had was often taken from them as a consequence of direct conflict and government policy, with significant impacts on specific roles as family protectors and providers for their community [22].

Aboriginal and Torres Strait Islander males are constantly being portrayed by perpetuating negative stereotypes such as being lazy, always drunk, are violent, uneducated, primitive, and being problems, all of which can hinder improvements to their health status and has led to the development of health and social policies that continue to suggest that these men are responsible a range of issues facing Indigenous families and communities. Consequently, health disparity is "being seen as a result of Aboriginal people's own failings. Worse still, they are being actively marginalized from influencing any path to potential solutions"[24] (p.97).

Primary health care services are critical to providing both clinical and social and emotional support for Aboriginal and Torres Strait Islander people. Brown suggests that "improving access to primary care stands as a critical target for improving health status among Indigenous Australians"[25] (p.815). However, primary health care services remain underutilized by Aboriginal and Torres Strait Islander men [26-28]. The reasons for this are not well documented or described and are likely to be complex. Current health system approaches fail to acknowledge that Aboriginal and Torres Strait Islander men have requirements for accessing and utilizing health systems that are different to Aboriginal and Torres Strait Islander women and their non-Indigenous counterparts [24]. Strategies are required to improve access and ultimately health outcomes among Aboriginal and Torres Strait islander men.

In Australia, health systems need to acknowledge the needs of all of their clients if the health and wellbeing of all Australians is to improve. However, such a health system cannot exist "without consideration of the ways in which culture intersects with issues of poverty and equity, including access and utilization of health care, individual and institutional racism, and a lack of cultural competence on the part of health providers and programs"[17] (p.2). Unfortunately, little action has been taken in this regard. The reorienting of services to decrease or remove barriers to care, and ensuring that the services are acceptable, of high quality and sensitive to the needs and demands of Aboriginal and Torres Strait Islander men remains a difficult task [25].

To meet the needs of Aboriginal and Torres Strait Islander people, Aboriginal Community Controlled Health Services (ACCHS) have been established [29]. There are 143 ACCHS in Australia, providing comprehensive primary health care services to local Aboriginal and Torres Strait Islander people [29]. The ACCHS are controlled by local community representatives and 'represent the only truly effective and culturally valid mode of delivering effective and sustainable primary health care services to Aboriginal Peoples' [29]. Similar comprehensive Indigenous primary health care services have also been established in New Zealand, Canada and America [30].

This review aims to (i) better understand the utilization of primary health care services by Indigenous men, and (ii) assess the effectiveness of strategies aimed at increasing the utilization of primary health care services by Indigenous men. This review had two research questions: 1) What factors impact the utilization of primary health care services by Indigenous men? 2) What strategies have been implemented to increase utilization of primary health care services by Indigenous men and how effective were they? 


\section{Methods}

Prior to commencing the review, a search of the Joanna Briggs Database of Systematic Reviews and Implementation Reports, the Cochrane Library, CINAHL, PubMed and PROSPERO revealed that no systematic review (either published or underway) has been conducted on this topic.

The authors developed and published a review protocol for this comprehensive systematic review [31]. This comprehensive literature review was guided by the Joanna Briggs Institute guidelines for systematic review and synthesis of qualitative data [32]. Studies from New Zealand, Canada and America were also included in the review due to the countries shared experience with colonization and their high disparity of health and wellbeing between the Indigenous and non-Indigenous peoples within each country.

\section{Inclusion criteria}

Each research question had their own inclusion criteria. Only the criteria related to the types of participants/ population were the same for both searches.

\section{Question 1: What factors impact the utilization of primary health care services by Indigenous men?}

\section{Types of participants/population}

Papers will be included if most of the participants in the study are men (aged 18 years and older) and are Indigenous to Australia (Aboriginal and/or Torres Strait Islander), New Zealand (Maori), Canada (First Nations) and America (native American).

\section{Phenomena of interest}

Studies that investigate the experience of clients with primary health care services will be included.

\section{Context}

Qualitative studies that explore client views or experiences relating to barriers and enablers to access or their experience with primary health care services will be included.

\section{Types of studies}

Qualitative studies to be included will be descriptive, ethnography, phenomenology and grounded theory studies, action research and evaluations, including developmental evaluations.

Published expert opinion will also be considered for inclusion.

Question 2: 2) What strategies have been implemented to increase utilization of primary health care services by Indigenous men and how effective were they?

\section{Types of participants/population}

Papers will be included if most of the participants in the study are men (aged 18 years and older) and are Indigenous to Australia (Aboriginal and/or Torres Strait Islander), New Zealand (Maori), Canada (First Nations) and America (native American).

\section{Types of intervention}

The review will consider studies on services that implement strategies or programs to increase health service utilization by Indigenous men:

Quantitative component: studies that evaluate health service utilization/access.

Qualitative component: studies that investigate client views or experiences related to these strategies.

\section{Context}

The review will consider studies whose context is primary health care services.

Acute care, chronic disease management, tertiary care or short-term rehabilitation clinics will not be considered.

\section{Comparator}

The quantitative component of this study will consider studies that evaluate and investigate primary health care services that implement a strategy to increase service utilization by Indigenous men. This may be a group of men who received the strategy compared to a group of men who did not receive the strategy or a study that compares services that did and did not receive the strategy. This review will also consider studies that have no comparator.

\section{Types of outcomes}

The quantitative component of this question will consider studies that include, but not limited to, the following outcome measures; occasions of care and client numbers.

\section{Types of studies}

Quantitative studies to be included are randomized controlled trials, non-randomized controlled trials, economic evaluations and costing studies (including model-based studies), retrospective and prospective cohort studies, case control studies, health service studies, health service evaluations, analytic cross-sectional studies and descriptive epidemiological study designs.

Qualitative studies to be included will be descriptive, ethnography, phenomenology and grounded theory studies, action research and evaluations, including developmental evaluations.

Mixed methods studies will also be considered for this review.

Papers were included if they met the inclusion criteria for one of the review questions. Qualitative papers that 
had explored client views or experiences related to barriers and enablers to access or their experience with primary health care services were included for the first review question. Papers that described the implementation of strategies or programs that aimed to increase health service utilization by Indigenous men were included to answer review question two.

For this review a primary health care center was defined as a health service outside an inpatient setting where patients can directly access, such as general practices, outpatient treatment and allied health services. Studies that were based in an acute care setting, or were focused on participants with a chronic condition, tertiary care or rehabilitation clinic were not included. Mixed methods publications that included a qualitative component which met the inclusion criteria were also included.

Expert opinion publications were reviewed if they discussed/offered opinions to the barriers and enablers for Aboriginal and Torres Strait Islander men utilizing primary health care services and were authored by Aboriginal and Torres Strait Islander men. Advice from male Aboriginal and Torres Strait Islander health research experts was sought to confirm the papers author(s) were indeed considered experts in the field and were Aboriginal and/or Torres Strait Islander men. These expert opinion papers were assessed for quality and contributed to the discussion of the paper, however, as they are not research studies, they are not described in the results section of this review.

\section{Search strategy}

A four-step search strategy was employed to find peer-reviewed publications and grey literature. Key words (listed in the review protocol) were used to search PubMed to identify additional keywords and index terms [32]. A search was then undertaken across four databases; PubMed, CINAHL, Informit (Indigenous collection) and Embase. The following databases and websites were also searched for grey literature; ProQuest, Trove, the National Aboriginal Community Controlled Health Organisation website, Australian Indigenous HealthInf$o$ Net, National Library of Australia and the Lowitja Institute. The reference list of included publications was searched for additional studies. In addition, relevant experts were also asked if they were aware of additional missing studies. The final two steps did not result in additional papers being included.

The search strategy in PubMed was as follows, this was modified as required in the other databases: Indigenous[tiab] OR Aborigin*[tiab] OR Torres Strait Islander[tiab] OR Inuit[tiab] OR Maori[tiab] OR American Indian[tiab] OR Native American[tiab] OR First Nation[tiab] OR Oceanic Ancestry Group[Mesh] OR "American Native Continental Ancestry Group"[Mesh] AND strateg* OR utilis* OR access* OR approach* OR tactic* OR engag* OR intervent* OR program* AND Primary health[tiab] OR primary care[tiab] OR "Health Care Quality, Access, and Evaluation"[Mesh] OR "Primary health care"[Mesh] OR "Health Services, Indigenous"[Mesh]. The search of data bases was conducted on the 15th of March 2015, was restricted to those published in English, with no date restrictions.

The lead author, $\mathrm{KC}$, identified articles that appeared to meet the inclusion criteria from their title and abstract. The full text of these articles was retrieved and reviewed by $\mathrm{KC}$ and $\mathrm{SH}$ to confirm if they met the inclusion criteria.

\section{Assessment of methodological quality}

The methodological quality of included studies was assessed by $\mathrm{KC}$ and $\mathrm{SH}$ using standardized critical appraisal instruments. The Joanna Briggs Institute (JBI) have produced a suite of critical appraisal tools to assess the quality of publications for the purposes of systematic review. The suite includes tools designed for the review of different types of publications. Qualitative papers (or qualitative components of mixed methods papers) were assessed using the JBI Qualitative Assessment and Review Instrument (JBI-QARI) [32]. Textual papers were assessed using the JBI Narrative, Opinion and Text Assessment and Review Instrument (JBI-NOTARI) [32]. When the reviewers had differing opinions on an article's quality, it was resolved by discussion and if needed a third party was consulted.

\section{Data extraction}

Data extraction was assisted using standardized tools. JBI-QARI for qualitative data, and JBI-NOTARI for textual data [32]. Two reviewers each completed data extraction on the included papers, then cross-checked each for completion and accuracy.

\section{Data synthesis}

The articles that met the inclusion criteria for research question one was read several times over to extract the findings related to participants experiences with primary health care services. Information was extracted from the results and discussion sections of the papers. The factors impacting the three studies were combined as were findings that were the same or similar. The barriers and enablers for Indigenous men accessing primary health care services were grouped into organizing themes (Table 4). Data synthesis was not conducted on the expert opinion manuscripts, as they did not describe qualitative findings from a study, however, the manuscripts have contributed to the discussion. 


\section{Results}

\section{Study selection}

The search of databases found a total of 13,480 publications once duplicates were removed. The full text of 56 papers were retrieved which resulted in seven studies being included in the review. The extensive grey literature search did not retrieve any additional papers. The search results are displayed in Fig. 1.

Of the seven included articles, one was a mixed methods study [26], three involved qualitative methods [33-35] and the other three were narrative opinion papers $[27,28,36]$. Two of the qualitative papers were from the same study [34, 35]. No studies were found that met the inclusion criteria for question 2 ; implemented strategies to increase utilization of primary health care services by Indigenous men.

\section{Methodological quality}

The methodological quality of the papers was assessed using the Joanna Briggs Institute (JBI) QARI Critical Appraisal Checklist for the Interpretive \& Critical Research
[32]. The quality assessment of the qualitative papers, and qualitative component of the mixed methods paper that met the inclusion criteria are presented in Table 1. Only Adams et al. mentioned how important "the insider/outsider status of the lead researcher (MJA) was pivotal to the study" [26] (p.33). The other three papers [33-35] failed to address the researchers influence on the study and vice-versa, that is, the role or influence of the researcher on the study and the study's influence on the researcher, was not critically explored. Hughes 2004 [33] also failed to include evidence that the research had ethics approval.

The expert opinion pieces $[27,28,36]$ that met the inclusion criteria were assessed for quality using the JBI Critical Appraisal checklist for Narrative, Expert Opinion and Text tool. The results of the assessment are displayed in Table 2. The methodological quality assessment tool for expert opinion manuscripts asks if the source of the opinion has standing in the field. After consultation with experts by the lead author, it must be acknowledged that at the time the article was published, Briscoe [27] was

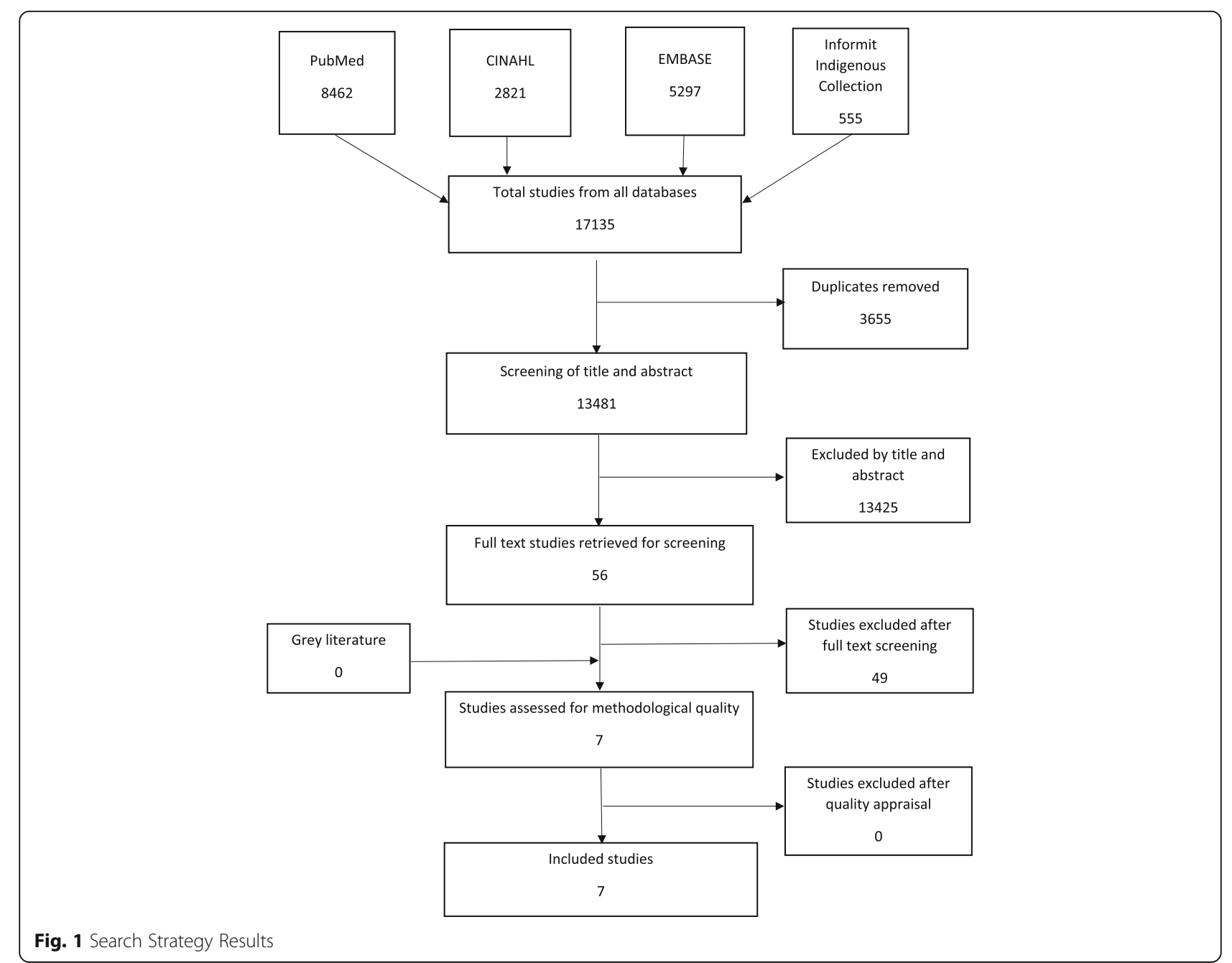




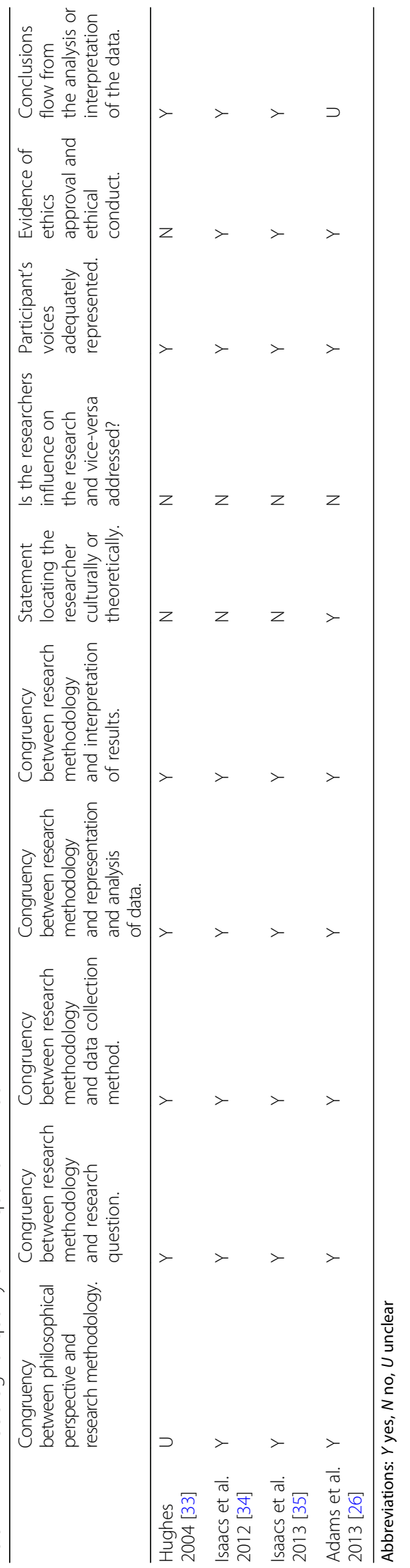


Table 2 Methodological quality of the expert opinion manuscripts

\begin{tabular}{|c|c|c|c|c|c|c|c|}
\hline & $\begin{array}{l}\text { Is the opinion } \\
\text { clearly identified? }\end{array}$ & $\begin{array}{l}\text { Does the source } \\
\text { of the opinion } \\
\text { have standing } \\
\text { in the field? }\end{array}$ & $\begin{array}{l}\text { Are the interests } \\
\text { of the patients } \\
\text { the central focus? }\end{array}$ & $\begin{array}{l}\text { Is the opinion's } \\
\text { basis in logic/ } \\
\text { experience } \\
\text { clearly argued? }\end{array}$ & $\begin{array}{l}\text { Is the argument } \\
\text { development } \\
\text { analytical? }\end{array}$ & $\begin{array}{l}\text { Is the reference to } \\
\text { the extant literature/ } \\
\text { evidence and any } \\
\text { congruency with it } \\
\text { logically defended? }\end{array}$ & $\begin{array}{l}\text { Is the opinion } \\
\text { supported } \\
\text { by peers? }\end{array}$ \\
\hline Briscoe 2000 [27] & Y & $U$ & Y & $Y$ & $Y$ & $\mathrm{Y}$ & $Y$ \\
\hline Hayman 2000 [28] & Y & Y & Y & Y & Y & Y & Y \\
\hline $\begin{array}{l}\text { Wenitong \& Adams } \\
2014 \text { [36] }\end{array}$ & Y & Y & Y & Y & Y & Y & Y \\
\hline
\end{tabular}

Abbreviations $Y$ yes, $N$ no, $U$ unclear

considered to have important standing in the field of Indigenous men's health. In saying this, his role in contemporary research and health policy and practice is less clear. As such, for the purposes of this appraisal the question was answered as 'unclear' for Briscoe's [27] manuscript.

It should be noted that the methodological quality can only be judged on what was published in the manuscript and is not necessarily an accurate reflection on the quality of the study.

\section{Characteristics of included studies}

The four manuscripts that included qualitative research methods [26, 33-35] describe three studies. As stipulated in the review protocol manuscripts related to the same study have been combined for the description of study characteristics and results [31].

The basic study characteristics have been summarized in Table 3. All studies included only Indigenous men. Isaacs et al. [34, 35] and Adams et al.'s [26] studies were conducted in Australia, Isaac et al. [34, 35] in Victoria in an urban setting, and Adams et al.'s [26] across urban, rural and remote communities in Queensland and the Northern Territory. Hughes's [33] study was conducted in Hawaii in both rural and urban settings.

Isaac et al.'s [34, 35] study focused on improving the accessibility of mainstream mental health services by Indigenous men. Adams et al.'s [26] study focused on Indigenous men accessing reproductive health services, whilst Hughes [33] focused on health seeking behaviors of Indigenous men to inform future effective cancer-related programs. All studies [26, 33-35] identified factors that impact Indigenous men accessing primary health care services.

The findings of the qualitative studies [26, 33-35] have been classified under four organizing themes which relate to health services, attitudes, knowledge and other. The health services theme included the services provided, service settings and the health service staff. The 'Attitudinal' theme comprised of the attitudes of Indigenous men and their communities. 'Knowledge' related to Indigenous men's and the community's knowledge and available information. An additional category for findings that fell outside of these three organizing themes was labelled 'Other' (Table 4).
The three studies [26, 33-35] found that participants felt there were barriers directly related to the health services and staff. Participants felt services were culturally inappropriate, racially discriminatory, and lacked traditional healing, Indigenous health professionals and gender specific staff. Past experiences with services also influenced the men's likeliness to access services, with negative experiences reducing their likelihood to return. Isaacs et al.'s [34, 35] study also found that Indigenous men were utilizing alternative coping strategies, including destructive behaviors such as alcohol and other substance use rather than accessing health services.

Distrust was a common theme; distrust of services, their staff or perceived lack of confidentially were factors negatively impacting access. Two studies [33-35] identified difficulty in obtaining an appointment or the long wait times for appointments to be barriers. Hughes et al. [33] found additional barriers to access including conflicting priorities, a lack of reminders for appointments, medical bureaucracy and difficulty finding parking. Beyond this they identified a lack of services, including specialty services in rural areas and the distance and absence of transport limited access to services.

The attitudes of Indigenous men and their communities influenced their help seeking behaviors. Shame, fear and stigma were commonly identified barriers. Shame or embarrassment prevented Indigenous men from talking about their health problems and in some cases from contacting or accessing health services at all. Fear was associated with breaches of confidentiality, fear of hospitals, procedures, receiving bad health news, and fear of being labelled by others. Stigma, in relation to sensitive health issues (mental health and sexual health) was identified as a barrier to health seeking behavior.

Hughes et al.'s [33] study identified barriers related to health insurance coverage and how some men felt discriminated against in relation to this coverage, "eight men commented on how they felt at the doctor's office, with only two saying they were made to feel comfortable and six saying they felt rushed, ignored or discriminated against because of their insurance coverage"[33] (p. 179). Unfortunately, there was no information regarding the exact type of discrimination experienced by the six men. 
Table $\mathbf{3}$ Characteristics of the qualitative studies

\begin{tabular}{|c|c|c|c|c|}
\hline Reference & Study design and objective(s) & Participants & Setting/context & Finding \\
\hline Hughes 2004 [33] & $\begin{array}{l}\text { Qualitative } \\
\text { To identify modifiable barriers } \\
\text { and to use men's ideas to } \\
\text { develop effective cancer- } \\
\text { related programs for Hawaiian } \\
\text { men. }\end{array}$ & $\begin{array}{l}\text { Native Hawaiian men aged } 22 \\
\text { to } 75 \text { participated in four, } \\
\text { semi-structured focus groups } \\
(\mathrm{N}=54) \text {. }\end{array}$ & $\begin{array}{l}\text { Three urban and rural focus } \\
\text { group on the island of O'ahu } \\
\text { and one group on the island } \\
\text { of Hawai'i. } \\
\text { All focus group interviews } \\
\text { were conducted at community } \\
\text { locations not involved in the } \\
\text { delivery of health care service. }\end{array}$ & $\begin{array}{l}\text { Study findings suggests that } \\
\text { men postpone healthcare } \\
\text { services for many reasons, } \\
\text { some of which can be } \\
\text { addressed through programs. }\end{array}$ \\
\hline $\begin{array}{l}\text { Isaacs et al. } 2012 \\
\text { [34] \& } \\
\text { Isaacs et al. } 2013 \\
\text { [35] }\end{array}$ & $\begin{array}{l}\text { Qualitative Description } \\
\text { Describe the perceptions of } \\
\text { Aboriginal people and mental } \\
\text { health personnel on ways to } \\
\text { improve } \\
\text { Aboriginal men's access to } \\
\text { mainstream mental health } \\
\text { services. }\end{array}$ & $\begin{array}{l}\text { Interviews: } \\
17 \text { Aboriginal male participants } \\
(5 \text { Aboriginal mental health } \\
\text { clients, } 5 \text { community } \\
\text { members, } 2 \text { cultural advisors, } 2 \\
\text { Aboriginal carers of men } \\
\text { diagnosed with a mental } \\
\text { illness, } 1 \text { Koori Hospital Liaison } \\
\text { Officer, and } 2 \text { social and } \\
\text { emotional wellbeing workers. } \\
\text { Focus Groups: } \\
3 \text { community mental health } \\
\text { team's members }(\mathrm{N}=8,10,6)\end{array}$ & $\begin{array}{l}\text { Victoria, Australia (urban). } \\
\text { Interviews: } \\
\text { University, Aboriginal } \\
\text { Organizations and } 3 \\
\text { conducted at the participant's } \\
\text { home. } \\
\text { Focus Groups: } \\
\text { The teams' Aboriginal } \\
\text { Organization. }\end{array}$ & $\begin{array}{l}\text { Barriers to help seeking by } \\
\text { Aboriginal men with mental } \\
\text { health problems were } \\
\text { identified. } \\
\text { Mismatches between } \\
\text { mainstream mental health } \\
\text { services and the mental health } \\
\text { needs of Aboriginal men were } \\
\text { identified along with some } \\
\text { solutions. } \\
\text { Mismatches included barriers } \\
\text { to gaining entry, barriers to } \\
\text { engaging with services and } \\
\text { staffing problems in the } \\
\text { service. } \\
\text { Potential solutions included } \\
\text { building the confidence of } \\
\text { men in the services, } \\
\text { developing relationships with } \\
\text { the community and } \\
\text { strengthening the role of the } \\
\text { Koori Mental Health Liaison } \\
\text { Officers (KMHLOs). }\end{array}$ \\
\hline $\begin{array}{l}\text { Adams et al. } 2013 \\
\text { [26] }\end{array}$ & $\begin{array}{l}\text { Mixed Methods } \\
\text { To better understand help- } \\
\text { seeking behaviors and } \\
\text { reproductive health issues } \\
\text { among Aboriginal and Torres } \\
\text { Strait Islander men. } \\
\text { To report the prevalence of } \\
\text { erectile dysfunction, and the } \\
\text { possible determinants of } \\
\text { erectile dysfunction and } \\
\text { prostate health. }\end{array}$ & $\begin{array}{l}\text { Questionnaires: } \\
\mathrm{N}=293 \text { Aboriginal and Torres } \\
\text { Strait Islander men, aged 18- } \\
74 \text {. (Includes the interviews } \\
\text { and focus group participants). } \\
\text { Interviews: } \\
18 \text { men ( } 29-45 \text { years old). } \\
\text { Focus Groups: } \\
\mathrm{N}=20 \text { in each group (Three } \\
\text { men's groups and one } \\
\text { women's group). }\end{array}$ & $\begin{array}{l}\text { Urban, rural and remote } \\
\text { communities from Darwin } \\
\text { (urban), Tiwi Islands (remote), } \\
\text { Cairns (urban), Yarrabah } \\
\text { (remote), Brisbane (urban), } \\
\text { Caloundra (rural), and Hervey } \\
\text { Bay (rural). }\end{array}$ & $\begin{array}{l}\text { Diabetes, heart disease and } \\
\text { high blood pressure frequently } \\
\text { reported by the men in the } \\
\text { study and high rates of } \\
\text { chronic disease coexist with } \\
\text { reproductive health problems. } \\
\text { Study highlights the low rate } \\
\text { of men seeking help for } \\
\text { erectile dysfunction. } \\
\text { Increases in reported erectile } \\
\text { problems prevalence increased } \\
\text { with age. } \\
\text { Study provides insights to the } \\
\text { barriers to seeking help for } \\
\text { reproductive disorders and } \\
\text { may point ways to improve } \\
\text { access to health services. }\end{array}$ \\
\hline
\end{tabular}

Participants from Hughes et al. [33] also found that health preventative checks could be reassuring and that seeing a health provider they did not know can reduce shame. Further, participants in this study identified a potential enabler of a 24-h toll-free number for anonymous advice from a doctor for personal and sensitive health concerns would improve health seeking behaviors. However, the type of doctor (male, female or Indigenous, non-Indigenous) was not mentioned.

The studies [26, 33-35] concluded that additional knowledge would improve service access; not knowing the importance of health checks or being able to identify health problems were factors that reduced primary health care utilization. One study [33] also found that additional information on the health services and clinics would also be beneficial.

\section{Discussion}

It has been well documented that the introduction of western diseases, enforced policies of genocide, assimilation, dispossession and deprivation, have all contributed to the poor health of Indigenous people in many countries [20,37, 38]. The on-going colonization process continues to be a catalyst towards the poor health and social and emotional wellbeing of Indigenous people [11, $12,14-16,18,19]$. Health services play a significant role 
Table 4 Factors impacting health seeking behaviors

\begin{tabular}{|c|c|c|c|c|}
\hline Study & Health Services & Attitudinal & Knowledge & Other \\
\hline Hughes 2004 [33] & $\begin{array}{l}\text { Distance to services and lack of } \\
\text { transport. } \\
\text { Lack of traditional healing } \\
\text { services. } \\
\text { Difficulty getting an appointment. } \\
\text { Would like to be able to call a } \\
\text { doctor } 24 \text {-hours a day on a toll- } \\
\text { free number for anonymous } \\
\text { advice for personal and sensitive } \\
\text { health concerns. } \\
\text { Lack of specialty services in rural } \\
\text { areas. } \\
\text { Past experiences of personal } \\
\text { interactions with health personnel } \\
\text { (positive and negative). } \\
\text { Lack of Native Hawaiian health } \\
\text { professionals. } \\
\text { Physicians need to listen more, } \\
\text { have a sense of humor and be } \\
\text { more honest. }\end{array}$ & $\begin{array}{l}\text { Fear, shame, embarrassment } \\
\text { and distrust. } \\
\text { Too embarrassed to seek } \\
\text { help for sexual health } \\
\text { problems, substance misuse } \\
\text { and mental health services. } \\
\text { Preventative visits are } \\
\text { reassuring. } \\
\text { Reluctant to find out } \\
\text { something is wrong. } \\
\text { Discomfort with some } \\
\text { procedures. } \\
\text { Less shame if you don't } \\
\text { know the service provider. }\end{array}$ & $\begin{array}{l}\text { Lack of information on } \\
\text { services from health } \\
\text { institutions and clinics. } \\
\text { Participant's knowledge of } \\
\text { the importance of annual } \\
\text { health checks. }\end{array}$ & $\begin{array}{l}\text { Financial issues; cost and } \\
\text { health insurance coverage. } \\
\text { Feeling rushed, ignored or } \\
\text { discriminated against } \\
\text { because of their insurance } \\
\text { coverage. } \\
\text { Conflicting priorities. } \\
\text { Lack of reminders. } \\
\text { Medical bureaucracy. } \\
\text { Difficulty finding parking. }\end{array}$ \\
\hline $\begin{array}{l}\text { Isaacs et al. } 2012 \text { [34] } \\
\& \text { Isaacs et al. } 2013 \\
\text { [35] }\end{array}$ & $\begin{array}{l}\text { Having to wait for an } \\
\text { appointment. } \\
\text { Past negative experiences with } \\
\text { health services/ hospitals. } \\
\text { Lack of trust with hospitals and } \\
\text { health services. } \\
\text { Lack of confidentiality. } \\
\text { Racial discrimination within } \\
\text { services. }\end{array}$ & $\begin{array}{l}\text { Distrust of health services } \\
\text { and staff. } \\
\text { Shame contacting services. } \\
\text { Fear of hospitals and health } \\
\text { services. } \\
\text { Need to safe-guard their role } \\
\text { in society. } \\
\text { Peer pressure. } \\
\text { Stigma. } \\
\text { Fear of being labelled } \\
\text { 'mental' by community. } \\
\text { Perceived need to be } \\
\text { 'strong'. }\end{array}$ & $\begin{array}{l}\text { Difficulty recognizing } \\
\text { mental health problems. }\end{array}$ & $\begin{array}{l}\text { Availability of alternative } \\
\text { coping strategies; alcohol } \\
\text { and other substances. }\end{array}$ \\
\hline Adams et al. 2013 [26] & $\begin{array}{l}\text { Lack of culturally appropriate } \\
\text { health services. } \\
\text { Culturally appropriate and gender } \\
\text { specific staff required. }\end{array}$ & $\begin{array}{l}\text { Shame, embarrassment and } \\
\text { low self-esteem limits ability } \\
\text { to talk about health } \\
\text { problems. } \\
\text { Fear of lack of confidentiality. } \\
\text { Stigma about sexual health } \\
\text { problems. }\end{array}$ & $\begin{array}{l}\text { Limited education about } \\
\text { erectile dysfunction is } \\
\text { available. }\end{array}$ & \\
\hline
\end{tabular}

in maintaining the health and wellbeing of individuals and populations. Their effectiveness is determined by several factors, none more so than their reach. Aboriginal and Torres Strait Islanders are known to utilize health services less often than non-Indigenous Australians, with Aboriginal and Torres Strait Islander men the population with the lowest utilization. The studies reviewed found that there are areas that could be improved to increase the accessibility of health services by Indigenous men. It is important to note that barriers to accessing services and negative experiences reduces the likeliness of patients returning and can lead to unhealthy coping strategies.

Modifications to primary health care services can reduce barriers for Indigenous men accessing care. Interviews with health service users provide valuable information identifying barriers, enablers and identifying potential strategies to improve service utilization. Common themes from the qualitative studies were Indigenous men feeling that services and staff were culturally inappropriate and racially discriminatory. Strategies to improve cultural appropriateness discussed by the research papers and Wenitong et al., include cultural safety/ competency training and the employment and utilization of Indigenous health staff. The re-orientation of health services to suit Indigenous men should be a collaborative process involving local Indigenous men and relevant stakeholders.

Negative attitudes that Indigenous men have about primary health care services impact their utilization. Indigenous men report feeling shame or that it is inappropriateness to discuss health issues, especially for issues such as sexual health and mental health, with a female health professional. Sometimes men want to speak to men and this can be a major barrier for Indigenous men. All expert commentaries (Briscoe, Hayman, Wenitong) discussed the importance of employing gender specific staff, especially for sensitive health issues. Examples of gender specific primary health care services and men's 
groups were also discussed as examples of successful strategies for reducing shame and increasing the utilization of primary health care services by Indigenous men. The stigma around some health issues, such as mental health and sexual health is also a barrier to accessing services. The shifting of social norms around such stigmas will take significant time, in the meantime primary health care services should acknowledge the local stigmas that exist and work with local Indigenous men to find ways to make accessing service more appropriate.

There can also be feeling of distrust, particularly around confidentiality within the service. This is likely to be due to past experiences or community rumors. Primary health care services need to be aware of this, ensure all staff are following the strictest protocols for protecting client's privacy and recognize that some staff that have relationships with clients may be inappropriate to be involved in the delivery of their care, data entry and handling of their information. Increasing the familiarity of Indigenous men with the service and staff may also help reduce feels of distrust. Participants from the Isaacs et al. study suggested group visits to services so that men become familiar with the services and importantly the staff [34].

There is a lack of information about health services available at local primary health care services and understanding the benefits of utilizing them. It was found that men feel that they do not have enough information on when to go and for what. Investing in education for men in these areas to help Indigenous men recognize health issues that require attention, the importance of annual health checks and where to go for what may increase the utilization of primary health care services by Indigenous men.

There are limitations to this study. The search for peer-reviewed literature was limited to four databases and did not include a search for online theses. The search for grey literature was restricted to Australia, likewise only expert opinions from Australian Aboriginal and/or Torres Strait Islander health experts were included. Although the review included literature from New Zealand, Canada and America, the purpose of the review is to inform primary health care services within the Australian context. The researchers being situated in Australia also reduced the ability to capture grey literature from other countries. Expert opinions published by non-Indigenous authors were not included, this decision was made to privilege Aboriginal and Torres Strait Islander voices and to highlight the importance of Indigenous leadership to improve Indigenous health [39].

There is a current lack of published research in this area. The inclusion criteria for this review only included papers where men were majority of the participants (over 50\%). This included publications that included some male voices within broader papers of which most of the responses were from women. The research included [26, 33-35] in this literature review has been conducted across multiple sites in Australia and in Hawai' $i$, throughout urban, rural and remote settings. One of the studies was specific to mental health services and another was specific to sexual health, therefore the results may not be generalizable to primary health care services.

\section{Conclusions}

The literature search found limited published research meeting the inclusion criteria. The factors impacting primary health care utilization described by Indigenous male participants were found within three studies [26, 33-35]. In addition, the search found three expert opinion papers $[27,28,36]$ but no published literature was found describing studies that have implemented and accessed the effectiveness of strategies to improve primary health care utilization by Indigenous men.

Of the studies identified, the factors impacting primary health care utilization shared many similarities. Indigenous men described factors impacting utilization which were categorized into the following organizing themes; health services, attitudes of Indigenous men and knowledge. Many of these findings echoed the sentiments of the three expert opinion papers $[27,28,36]$.

The studies reviewed found that there are areas that could be improved to increase the accessibility of health services by Indigenous men. There were common themes found by the research including; the need for culturally appropriate services and staff, increased knowledge, distrust and fear of health services, shame and stigma especially around sensitive health issues. The evidence also highlighted the need for gender specific services and male health providers. Even though there is limited research that explores the barriers for health service utilization by Indigenous men, the evidence available supports the anecdotal evidence and expert opinion. The barriers and enablers identified in this review should be used to inform the development of new strategies to improve the utilization of health services by Indigenous men.

Currently there is insufficient data available on the utilization of primary health care services by Indigenous men. It is widely acknowledged that Indigenous men are underutilizing services, however, unless this information is shared we will not be able to track progress in the improvements of service utilization. Future research should focus on evaluating the implementation of men specific utilization strategies. It is through such evidence-based research that subsequent policies and programs can be made and implemented to improve Indigenous men's health. 


\section{Abbreviations}

JBI: Joanna Briggs Institute; JBI-NOTARI: Joanna Briggs Institute Narrative, Opinion and Text Assessment and Review Instrument; JBI-QARI: Joanna Briggs Institute Qualitative Assessment and Review Instrument

\section{Acknowledgements}

KC would like to acknowledge the significant mentoring and administrative support from the Wardliparingga Aboriginal Research Unit within the South Australian Health and Medical Research Institute (SAHMRI). KC would also like to acknowledge the support received from the Freemasons Foundation Centre for Men's Health, Faculty of Health Sciences, University of Adelaide.

\section{Funding}

KC was supported by a Fellowship (100702) from the National Heart Foundation of Australia. Financial support for this review was received from Oxfam Health and Wellbeing Supporting Innovating Grants 2014. KC would like to acknowledge the capacity building support received from the Centre for Research Excellence in Aboriginal Sexual Health and Blood Borne Viruses CREASHBBV (National Health and Medical Research Council CRE Grant \#1100302). AB is supported by a Viertel Senior Medical Research Fellowship. Work supported in part by NHMRC CRE APP1061242.

\section{Authors' contributions}

$\mathrm{KC}, \mathrm{AB}$ and $\mathrm{GW}$ devised the review question and the search strategy. $\mathrm{KC}$ performed the search and reviewed abstracts for inclusion. $\mathrm{KC}$ and $\mathrm{SH}$ conducted full text screening of the 56-texts retrieved by KC. KC and SH reached agreement on the final papers chosen for this review. KC completed first draft of paper. $A B$ and GW provided guidance throughout literature review, including the structure for the synthesis of information. AB, GW and SH assisted with the drafting and refinement of the paper. All authors read and approved the final manuscript.

\section{Ethics approval and consent to participate}

Not applicable.

\section{Consent for publications}

Not applicable.

\section{Competing interests}

The authors declare that they have no conflict of interest.

\section{Publisher's Note}

Springer Nature remains neutral with regard to jurisdictional claims in published maps and institutional affiliations.

\section{Author details}

${ }^{1}$ Wardliparingga Aboriginal Research Unit, South Australian Health and Medical Research Institute, Adelaide, Australia. ${ }^{2}$ Freemasons Foundation Centre for Men's Health, University of Adelaide, Adelaide, Australia. ${ }^{3}$ Centre of Research Excellence in Aboriginal Chronic Disease Knowledge Translation and Exchange (CREATE), University of Adelaide, Adelaide, Australia. ${ }^{4}$ Sansom Institute for Health Research, University of South Australia, Adelaide, Australia.

\section{Received: 5 February 2018 Accepted: 4 October 2018}

\section{Published online: 23 October 2018}

\section{References}

1. Bramley D, Hebert P, Jackson R, Chassin M. Indigenous disparities in diseasespecific mortality, a cross-country comparison: New Zealand, Australia Canada, and the United States. N Z Med J. 2004;117(1207):U1215.

2. Australian Institute of Health and Welfare, editor. The health and welfare of Australia's Aboriginal and Torres Strait Islander peoples: 2015. In: Australian Institute of Health and Welfare. Canberra: Australian Institute of Health and Welfare. p. 2015.

3. Phillips B, Morrell S, Taylor R, Daniels J. A review of life expectancy and infant mortality estimations for Australian aboriginal people. BMC Public Health. 2014;14(1):1.

4. Australian Institute of Health and Welfare (AlHW). Comparing life expectancy of indigenous people in Australia, New Zealand, Canada and the United States: conceptual, methodological and data issues. Canberra: AlHW; 2011. p. 48.
5. UN Permanent Forum on Indigenous Issues (UNPFII). State of the World's Indigenous Peoples, vol. 2018. New York: Department of Economic and Social Affairs; 2010.

6. Brown A, Walsh W, Lea T, Tonkin A. What becomes of the broken hearted? Coronary heart disease as a paradigm of cardiovascular disease and poor health among indigenous Australians. Heart Lung Circul. 2005;14(3):158-62.

7. Brown A, Scales U, Beever W, Rickards B, Rowley K, O'Dea K. Exploring the expression of depression and distress in aboriginal men in Central Australia: a qualitative study. BMC Psychiatry. 2012;12(1):1-13.

8. Adams M, Danks B. A positive approach to addressing indigenous male suicide in Australia. Aborig Islander Health Worker J. 2007;31(4):28-31.

9. Brown A. Addressing cardiovascular inequalities among indigenous Australians. Global Cardiol Scie Pract. 2012;2012(1):2.

10. Brown AD, Mentha R, Rowley KG, Skinner T, Davy C, O'Dea K. Depression in aboriginal men in Central Australia: adaptation of the patient health questionnaire 9. BMC Psychiatry. 2013;13(1):1-10.

11. Doyle K. Modes of colonisation and patterns of contemporary mental health: towards an understanding of Canadian aboriginal, Australian aboriginal and Maori peoples. Aborig Islander Health Worker J. 2011;35(1): 20-3.

12. Affairs HoRSCOA: Aboriginal health: report from the house of representatives standing committee on aboriginal affairs. In. Canberra; 1979.

13. Cavanaugh CL, Taylor CA, Keim KS, Clutter JE, Geraghty ME. Cultural perceptions of health and diabetes among native American men. J Health Care Poor Underserved. 2008;19(4):1029-43.

14. McCalman J, Tsey K, Wenitong M, Whiteside M, Haswell M, Cadet-James Y, Wilson A. Indigenous men's groups: what the literature says. Aborig Islander Health Worker J. 2006;30(3):9-13.

15. Patterson D. Yarrabah Men's health group. Aborig Islander Health Worker J. 2000;24(1):3.

16. Saunders M. Indigenous health, indigenous men: leadership and other bad medicine. Aborig Islander Health Worker J. 2003;27(6):10-3.

17. Tripp-Reimer T, Choi E, Kelley LS, Enslein JC. Cultural barriers to care: inverting the problem. In: Diabetes Spectrum, vol. 14; 2001. p. 13.

18. Wenitong M. Aboriginal and Torres Strait islander male health, wellbeing and leadership. Med J Aust. 2006;185(8):466-7.

19. Purdie N, Dudgeon P, Walker R: Working together: aboriginal and Torres Strait islander mental health and wellbeing principles and practice. Canberra; 2010.

20. Ball J. Indigenous Fathers' involvement in reconstituting "circles of care". Am J Community Psychol. 2010;45(1-2):124-38.

21. Ban P. Access and attitudes to health care of Torres Strait islanders living in mainland Australia. Austral J Primary Health. 2004;10(2):29-35.

22. New Research Explores Masculinity Among Indigenous Men. http://news. uoguelph.ca/2011/06/new-research-explores-masculinity-amongindigenous-men/. Accessed 8 May 2015.

23. Ricciardelli LA, Mellor D, McCabe MP, Mussap AJ, Hallford DJ, Tyler M. Promoting fit bodies, healthy eating and physical activity among indigenous Australian men: a study protocol. BMC Public Health. 2012; 12(1):1-9.

24. Brown A. Bridging the survival gap between indigenous and nonindigenous Australians: priorities for the road ahead. Heart Lung Circul. 2009;18(2):96-100

25. Brown A, Blashki G. Indigenous male health disadvantage-linking the heart and mind. Aust Fam Physician. 2005;34.

26. Adams M, Collins VR, Dunne MP, De Kretser DM, Holden CA. Male reproductive health disorders among aboriginal and Torres Strait islander men: a hidden problem? Med J Aust. 2013;198(1):33-8.

27. Briscoe A. Indigenous Men's health: access strategy. Aborig Islander Health Worker J. 2000;24(1):7-11.

28. Hayman N. Medical and clinical issues for indigenous men. Aborig Islander Health Worker J. 2000;24(1):4-6.

29. NACCHO Vision. http://www.naccho.org.au/about-nacho/naccho-vision/. Accessed 29 May 2017.

30. Harfield SG, Davy C, McArthur A, Munn Z, Brown A, Brown N. Characteristics of indigenous primary health care service delivery models: a systematic scoping review. Glob Health. 2018;14(1).

31. Canuto K, Harfield S, Brown A, Wittert G. Strategies that target the utilization of primary health care services by indigenous men in Australia, New Zealand, Canada and America: a comprehensive systematic review protocol. JBI Datab Syst Rev Implem Rep. 2015;13(9):95-111. 
32. Institute JB. Joanna Briggs Institute Reviewers Manual. Adelaide: Joanna Briggs Institute; 2014.

33. Hughes CK. Factors associated with health-seeking behaviors of native Hawaiian men. Pac Health Dialog. 2004;11(2):176-82.

34. Isaacs AN, Maybery D, Gruis H. Mental health services for aboriginal men: mismatches and solutions. Int J Ment Health Nurs. 2012;21(5):400-8.

35. Isaacs AN, Maybery D, Gruis H. Help seeking by aboriginal men who are mentally unwell: a pilot study. Early Interv Psychiatry. 2013;7(4):407-13.

36. Wenitong M, Adams M, Holden CA. Engaging aboriginal and Torres Strait islander men in primary care settings. Med J Aust. 2014;200(11):632-3.

37. Green D, Minchin L. Living on climate-changed country: indigenous health, well-being and climate change in remote Australian communities. EcoHealth. 2014;11(2):263-72.

38. Marrone $\mathrm{S}$. Understanding barriers to health care: a review of disparities in health care services among indigenous populations. 2007;66(3).

39. Ryan T: It's time to 'big note' indigenous health leaders. In: Health \& Wellbeing. 21 may 2018 edn: University of Melbourne; 2018.

Ready to submit your research? Choose BMC and benefit from:

- fast, convenient online submission

- thorough peer review by experienced researchers in your field

- rapid publication on acceptance

- support for research data, including large and complex data types

- gold Open Access which fosters wider collaboration and increased citations

- maximum visibility for your research: over $100 \mathrm{M}$ website views per year

At $\mathrm{BMC}$, research is always in progress.

Learn more biomedcentral.com/submissions 